\title{
The use of standardized assessment procedures in the evaluation of patients with multiple injuries
}

\author{
J. E. MURAT, N. HUTEN AND J. MESNY \\ Emergency Surgical Department, University Hospital, Tours, France
}

\section{SUMMARY}

The accuracy of diagnosis in multiple trauma can be greatly improved by the use of standardized assessment routines and standard documentation. In the two groups of patients reviewed the diagnostic error rate fell from $23 \%$ in the period $1979-1980$ to $8 \%$ for the period 1981-1982.

\section{INTRODUCTION}

The assessment and immediate care of a patient with multiple injuries is one of the most difficult areas of medical practice. The history and examination may be rushed, the patient require intensive resuscitation and the doctor have to perform a number of complex life-saving procedures. Errors are often made during this initial assessment (McLaren et al., 1983; Gilroy, 1984) and these errors can be fatal.

Therefore, it is clear that a systematic examination is of the utmost importance in this situation. The use of a standardized record form has been shown to increase the accuracy of diagnosis in abdominal pain (Gunn, 1976). We have studied the use of a standardized record form in the initial assessment of patients with multiple injuries. The aim was to use such a form to establish accurately the error rate and to see if once in use the form itself had any influence on the number of errors made.

English text prepared by: Dr $\mathcal{F}$. Wardrope, Accident and Emergency Department, The General Infirmary, Leeds, England

Correspondence: Dr F. E. Murat, Centre Hospitalier Regional de Tours, 37044 Tours Cedex, France 


\section{METHOD}

Since 1978 all patients with two or more serious injuries admitted to the Emergency Department of the Tours University Hospital have been recorded in special case notes.? The first two pages of these notes are used in the initial assessment. Figure 1 shows the first page of these notes. Most of the details may be entered with a single figure ando although there are 97 items on this page of the form, it can be completed in a couple of minutes. Other parts of the form contain diagrams which enable a pictorial record of the $\frac{\bar{\phi}}{\bar{\phi}}$ injuries to be made.

These notes are completed by the accident doctor; they accompany the patients ${ }^{2}$ throughout their stay in hospital and are used to chart their progress.

The forms were reviewed and a group of the most seriously injured patients $\vec{A}$ identified. These patients all had three or more serious injuries and a systolic blood pressure less than $90 \mathrm{~mm} \mathrm{Hg}$ on admission or a haematocrit less than 0.27 . The initial 3 . grading of the severity of the injury was made using the Abbreviated Injury Scaleiv (Baker et al., 1974). The end point of follow-up was the discharge from hospital or death.

The results of the follow-up were used to audit the performance of the accident unit ${ }_{-}^{\circ}$ staff. Any areas of difficulty were discussed at regular unit meetings. The junior staff 3 were involved in the evaluation of the forms. This served to introduce them to research $\frac{\widetilde{\alpha}}{\circ}$ and also drew their attention to the long-term results of the management of these $\overrightarrow{ }$ patients.

\section{RESULTS}

During the period 1979-1980 over 3000 cases with two or more serious injuries were $\overrightarrow{\vec{\circ}}$ examined, but only 116 met the requirements for inclusion in the study. In the period 3 1981-1982 407 patients satisfied the criteria for inclusion. The increase in numbers is due to the centralization of accident services in the University Hospital in 1980. Table 1 lists the trauma scores of the two groups. There are significantly more patients with a 3 trauma score above 15 in the second group $(p<0 \cdot 001)$.

Table 2 describes the diagnostic errors for the two periods. They are expressed as $a^{3}$. percentage of the total number of cases seen in that year. The improvement is most marked with injuries to the chest and abdomen.

Table 3 lists the actual errors missed, expressed as totals and as percentages.

The improvement is not so apparent in the proportion of limb fractures mis- $\frac{D}{2}$ diagnosed. Ten limb fractures were missed in the second group out of a total of $407 \bar{N}$ patients $(2.5 \%)$ while four fractures were not diagnosed in the first period when $116^{\circ}$ patients were included in the study $(3.5 \%)$. Other centres have reported similar N problems in the diagnosis of limb fractures in the seriously injured (McLaren et al., ${ }_{0}^{\omega}$ 1983). In these patients other injuries take precedence over limb fractures which are not immediately life threatening. However, recent work has indicated that the early recognition and treatment of these fractures can reduce the late mortality from fat $\stackrel{?}{+}$ embolism and other respiratory problems (Jansen et al., 1982). 
General examination

- pallor

- conjunctival pallor

Y N

$Y \quad N$

Y N

Y N

Y N

- cyanosed

- sweating

Respiratory state

- chest bruising

- tachypnoea

- dyspnoea

- asymmetrical

movement

- tenderness

- subcutaneous emphysema

- breath sounds not

heard

Y N

Y N

$Y N$

R L

R L

$Y N$

L. R
Neurological state

- coma scale :

$\begin{array}{llll}1 & 2 & 3 & 4\end{array}$

progress : stable - better - worse

Time unconscious

- neck stiffness

- convulsions

- decerebrate signs

- pupils - dilated

- motor deficit

- sensory deficit

- reflexes absent - arms

- knees

- ankles

- Babinsky

Circulatory state

\begin{tabular}{|l|}
\hline Time \\
\hline Pulse \\
\hline B.P. \\
\hline Urine \\
\hline C.V.P. \\
\hline
\end{tabular}

Injuries

Enter:

$W=$ Wound

$F=$ Fracture

$\mathrm{D}=$ Dislocation

Heart sounds : normal abnormal

Peripheral pulses : all present

absent - which?

Urine

Volume on admission

Haematuria

Abdomen - indicate the involved area - marks, bruising

- tenderness

- rigidity

- guarding

- p.v. or p.r. painful

- peritoneal lavage positive negative

- lumbar tenderness

L R

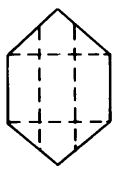

Skin signs

\begin{tabular}{|l|l|l|}
\hline \multicolumn{1}{l}{ Lkull } & & \\
\hline face & & \\
\hline shoulder & & \\
\hline arm & & \\
\hline elbow & & \\
\hline forearm & & \\
\hline wrist & & \\
\hline hand & & \\
\hline pelvis & & \\
\hline thigh & & \\
\hline knee & & \\
\hline leg & & \\
\hline ankle & & \\
\hline foot & & \\
\hline
\end{tabular}

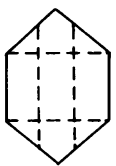

tenderness

$\begin{array}{ll}Y & N \\ Y & N \\ Y & N \\ L & R \\ \text { L } & R \\ Y & N \\ Y & N \\ L & R \\ \text { L } & R \\ \text { L } & R \\ \text { L } & R\end{array}$

$\begin{array}{ll}\mathrm{L} & R \\ \mathrm{~L} & \mathrm{R}\end{array}$

Spinal tenderness

$\begin{array}{llll}\text { cervical } & : & \mathrm{Y} & \mathrm{N} \\ \text { thoracolumbar } & : & \mathrm{Y} & \mathrm{N}\end{array}$

E.N.T

- bleeding from ears : $Y Y_{N} N$

- larynx : bruising : emphysema

Eyes

- lesion globe : $\mathrm{Y} N$

- lesion eyelid : Y N

Fig. 1 Multiple trauma diagnostic check-list. 
Table 1 Summed abbreviated injury scores

\begin{tabular}{ccc}
\hline Injury score & $\begin{array}{c}\text { Number of patients } \\
1979-1980\end{array}$ & $\begin{array}{c}\text { Number of patients } \\
1981-1982\end{array}$ \\
\hline$\geqslant 15$ & $11(10 \cdot 4 \%)$ & $110(27 \%)$ \\
$10-14$ & $50(43 \cdot 5 \%)$ & $150(38 \%)$ \\
$5-9$ & $50(43 \cdot 5 \%)$ & $137(34 \%)$ \\
$\leqslant 4$ & $4(3 \cdot 5 \%)$ & $10(2 \%)$ \\
\hline
\end{tabular}

Table 2 Diagnostic errors in major areas expressed as a percentage of the total number of cases in that period (actual no. cases)

\begin{tabular}{lrl}
\hline Area & $1979-1980$ & $1981-1982$ \\
\hline Abdomen & $8 \% \quad(9)$ & $2 \% \quad(9)$ \\
Chest & $9 \%(11)$ & $2.5 \%(10)$ \\
Fractures & $6 \%(7)$ & $3.5 \%(14)$ \\
Total & $23 \%(27)$ & $8 \% \quad(33)$ \\
\hline
\end{tabular}

Table 3 Numbers of lesions missed (percentage of total cases)

\begin{tabular}{|c|c|c|c|}
\hline & Missed lesions & $1979-1980$ & $1981-1982$ \\
\hline \multirow[t]{3}{*}{ Abdomen } & Ruptured spleen & $6(5 \cdot 2 \%)$ & $5(1 \cdot 2 \%)$ \\
\hline & Liver and pancreatic injury & $2(1 \cdot 7 \%)$ & $3(0 \cdot 7 \%)$ \\
\hline & Mesenteric bleeding & $1(0.9 \%)$ & $1(0 \cdot 2 \%)$ \\
\hline \multirow[t]{4}{*}{ Chest } & Pulmonary damage & $4(3 \cdot 4 \%)$ & $3(0 \cdot 7 \%)$ \\
\hline & Ruptured diaphragm & $3(2 \cdot 6 \%)$ & $3(0 \cdot 7 \%)$ \\
\hline & Aortic rupture & $2(1 \cdot 7 \%)$ & $1(0 \cdot 2 \%)$ \\
\hline & Myocardial damage & $2(1 \cdot 7 \%)$ & $3(0 \cdot 7 \%)$ \\
\hline \multirow[t]{3}{*}{ Fractures } & Limbs & $4(3.5 \%)$ & $10(2 \cdot 5 \%)$ \\
\hline & Spine & $2(1 \cdot 7 \%)$ & $2(0.5 \%)$ \\
\hline & Pelvis & $1(0.9 \%)$ & $2(0.5 \%)$ \\
\hline
\end{tabular}

Although it is not the purpose of this paper to compare mortality, it is gratifying to note that mortality in this group of severely injured patients fell from $33 \%$ in the firste. period to $20.6 \%$ in the second ( $p>0.001$ ).

\section{DISCUSSION}

The care of the patient with multiple injuries requires a high degree of skill and experience. The improvement in out-of-hospital resuscitation schemes like SAMU in 
France and the paramedics in the USA (Dove et al., 1982) must be matched by similar improvements in in-hospital care. Junior staff in the accident department on 6monthly or annual rotations may not have the experience necessary to manage these situations correctly. However, the use of the standardized assessment routine has helped our junior staff to improve their diagnostic accuracy in critically injured patients.

Primarily, the form serves as a framework for systematic examination of the patient. The basic approach to all medical problems of history-taking and physical examination is easily forgotten in the stress of the situation. Using the form as a check-list ensures that these essential requirements are not overlooked.

Secondly, the standardized notes provide an immediate record which will be easier to interpret when the patient is transferred to the care of other specialties. If the doctors involved in trauma care help to design the form then they can ensure that information important to their particular field is recorded from the time that the patient is first seen.

Finally, sound documentation is the basis for accurate medical audit. Any errors in diagnostic technique can be identified and appropriate action taken. We have found this system particularly helpful as follow-up information is readily available for case discussions and instruction for our junior staff.

The use of the standardized assessment routines is not the only factor in the reduction of our error rates. Centralization of accident services has meant that more of the seriously injured patients are being treated and in one specialized unit. The benefits of such centralization are well known to surgeons in the USA (Trunkey, 1984) and it has been recommended for the UK (Irving, 1982). Organization of trauma services at all levels increases efficiency and the subsequent care of the patient. Standardization of assessment routines in the accident and emergency department is part of this organization.

\section{REFERENCES}

Baker S. P., O’Neill B., Haddon W. \& Long W. B. (1974) The injury severity score: a method for describing the patient with multiple injuries and evaluating emergency care. fournal of Trauma 14, 187-96.

Dove D. B., Munoz E., Cuzner G., Altman R., Cardaci L., Stahl W. M. \& del Guercio L. R. M. (1982) Use of an emergency room operating room for resuscitation and immediate operative intervention of acutely ill patients. In Care of the Acutely Ill and Injured. A. K. Marsden \& D. H. Wilson (eds), pp. 171-6. Chichester, John Wiley and Sons.

Gilroy D. (1984) Deaths from blunt trauma. A review of 105 cases. Injury 15, 304-8.

Gunn A. A. (1976) The diagnosis of abdominal pain with computer analysis. Fournal of the Royal College of Surgeons of Edinburgh 21, 170-2.

Irving M. H. (1982) The care of emergencies in the United Kingdom. In Care of the Acutely Ill and Injured. A. K. Marsden \& D. H. Wilson (eds), pp. 1-14. Chichester, John Wiley and Sons.

Janson I., Erikson R. \& Liljedaik S. O. (1982) Primary fracture immobilisation as a method to prevent post traumatic pulmonary changes in the experimental model. Acta Chirurgica Scandanavica 148, 329-38.

McLaren C. A. N., Robertson C. \& Little K. (1983) Missed orthopaedic injuries in the resuscitation room. fournal of the Royal College of Surgeons of Edinburgh 28, 399-401.

Trunkey D. D. (1983) Trauma. Scientific American 249, $20-7$.

Received 26 June 1984; editorial comments to authors 26 fuly 1984; accepted for publication 13 August 1984 